\title{
A Review of Native Wild Bee Nutritional Health
}

\author{
Megan E. Leach and Frank Drummond (iD \\ 305 Deering Hall, School of Biology and Ecology, University of Maine, Orono, ME, USA \\ Correspondence should be addressed to Frank Drummond; fdrummond@maine.edu
}

Received 22 September 2018; Accepted 18 October 2018; Published 25 October 2018

Academic Editor: Béla Tóthmérész

Copyright (C) 2018 Megan E. Leach and Frank Drummond. This is an open access article distributed under the Creative Commons Attribution License, which permits unrestricted use, distribution, and reproduction in any medium, provided the original work is properly cited.

\begin{abstract}
Declines in wild and managed bee species richness and abundances have been observed throughout Europe and North America in recent decades. These declines have led to questions regarding pollination of wild and cultivated plants. In response to these concerns, efforts towards the conservation of pollinators have been initiated. Part of this conservation effort should be to provide the basic nutritional needs for bees. Nutrition plays one of the most important roles in bee growth, development, and reproduction. There is a large body of information regarding honey bee nutrition, whereas we lack nutritional information on native wild bees. Our knowledge of bumble bee nutritional needs has increased since the introduction of commercial rearing and sale of certain bumble bee species; however, there is still a lack of basic nutritional guidelines such as minimum dietary needs of proteins, amino acids, lipids, and sterols. The large difference in physiology and life history between honey bees and North American wild bees suggests that their nutritional requirements could be quite different.
\end{abstract}

\section{Introduction}

Pollination is mostly an example of a mutually beneficial relationship between plants and animals. Pollinators visit a flower to take nutrients while plants are provided with a pollination service. Bees pollinate a large percentage of flowering plants, providing pollination services to approximately $90 \%$ of wild plant species and $75 \%$ of global food crops, which constitute $35 \%$ of world crop production $[1,2]$. Both managed and wild bees are ecologically, culturally, and economically important organisms, but in recent decades some bee species have had population declines and, in extreme cases, extirpation [3-6]. Managed honey bees (Apis mellifera L.) have had an overall gain in the number of managed colonies worldwide but a decline in many developed countries $[5,7]$. However, even where the number of colonies has increased, annual colony losses are still high and health is highly compromised across the honey bees' geographic range $[8,9]$. Native wild bees are hard to identify and require experienced taxonomists and are therefore less studied and more difficult to quantify [10]. Bumble bee species are much larger in size than many of the small solitary bees and so are easier to detect in the landscape. Several studies on bumble bees have reported population declines as well as decreases in habitat ranges [1113]. There are currently two bee species listed on the IUCN red list (the IUCN Red List of Threatened Species ${ }^{\mathrm{TM}}$ is the most complete inventory of the global conservation status of plant and animal species throughout the world) and seven bee species recently listed as federally endangered in the United States, with several more species suggested for listing $[14,15]$.

Several factors negatively impact bee populations including pesticide exposure, habitat loss and/or degradation, predators, parasites, diseases, and climate change $[3,5,11,12]$. Although each of these factors acting alone has been shown to affect bee populations, it's more likely that bees are exposed to multiple stressors simultaneously [12]. Conservation, restoration, and protection of bee habitat across many different landscapes are needed to increase bee abundances and ensure pollination for both agricultural and nonagricultural native plant communities.

Bee forage is also a factor that affects bee abundance and health $[16,17]$. A lack of bee forage may cause bee populations to decrease or show signs of nutritional stress [18,19]. The goal of this literature review is to synthesize current knowledge on bee nutrition for different bee species and bring attention to gaps in knowledge that need to be addressed. This has been 
recently accomplished for honey bees [20, 21], so they will not be covered in our review, although on topics that lack information on native wild bees, studies on honey bees will be offered as a possible corollary for wild bees.

\section{Provisioning of Food by Eusocial and Solitary Bees}

Most of the nutritional information we have for bees comes from studies on the honey bee and more recently bumble bees, due to production of commercially available bumble bee colonies of Bombus terrestris L. and Bombus impatiens Cresson. There is little information on native wild solitary bees, which have very different life histories from eusocial bees. All bees, even kleptoparasitic bees, require that all nutritional requirements are provided by pollen and nectar and in a few cases plant oils, which will not be discussed in this review [20-22]. Pollen and nectar are required by both adult and larval stages and provide different nutrients for bees.

Life history traits for eusocial and solitary bees are very different, especially concerning the care and feeding of larvae. Michener [22] provides a good account of a common life history of this group of bees. Adult solitary bees collect nectar and pollen to feed themselves and to provision their progeny (provisioning takes place just prior to oviposition), but pollen and nectar are initially required by the adult female to develop ovaries and begin egg laying. The first activity of adults is emergence from the overwintering hibernacula, mating, and then females construct nests out of a range of materials, depending on the bee species. After nest completion, foraging commences with collection of nectar and pollen. A "loaf" or "bee-bread" is formed by mixing nectar, gut microbial symbionts, and pollen together which is then placed in a nest chamber with a single egg and is then sealed off. This process is repeated until a nest tunnel or cavity is full. Female adult bees eat pollen and nectar for their own nutrition throughout this period. Depending on the bee species, there may be one or several generations in a season. The overwintering stage of a bee depends on climate and species [22].

The life history of eusocial bees is very different and is described for bumble bees by Goulson [23] and for honey bees by Caron et al. [24]. Eusocial bees collect pollen and nectar for adult nutrition as well as brood rearing, but adults store pollen and nectar for their own sustenance, for the queen and drones, and in addition larvae are progressively provisioned rather than provided all food at once. In North America, the start of the bumble bee annual life cycle is initiated with queen emergence from overwintering refugia and then nest founding. The queen then commences foraging for pollen and nectar resulting in the development of her ovaries [25]. She then lays eggs and upon hatch, provisions brood (larvae) progressively and throughout their development until pupation. Newly emerged female workers collect pollen and nectar for themselves and brood (larvae) while males either do not forage and are provided food by the workers (honey bees), or forage solely for themselves. Workers with different roles in the colony may require different nutrient levels as is the case for honey bees $[20,26,27]$. For example, honey bee workers gradually switch from diets high in essential amino acids when they are newly emerged to carbohydrateheavy diets as they age. Nurse bees and foraging bees have been shown to exhibit different survival on diets high in essential amino acids, with nurses surviving high amino acid diets more readily than foraging bees [27]. It is not known if this is the case for other eusocial bee species, although in B. impatiens, percent lipid of the diet is correlated with body size, but not tasks within the colony [28].

\section{Larval Diets}

Maternal investment is an important aspect of bee development and in turn population success due to increased fitness with higher quality diet. It's a challenge to accurately measure whether bees intentionally provide their larvae higher quality diets, but there is evidence that this is the case. The influence of larval diets carries over to the adult life stage by affecting adult longevity, maturation, and fitness, but less so longevity because adult nutrition may overcome deficiencies from larval stage diet and nutrition [29].

In eusocial bees, the quality and quantity of pollen and nectar seem to dictate foraging activities. Honey bees monitor nectar and honey stores in the colony and adjust foraging behavior accordingly [30]. In bumble bees, it appears that pollen and nectar quality determine the rate of foraging and level of stores within a colony [31,32]. Pollen and nectar quality may also have an influence on the rate of resource collection [33, 34]. Bumble bees have been observed to monitor honey pots and pollen stores; then adjust the number of foraging individuals and collection behaviors accordingly $[31,32]$. In solitary bees, the amount of nectar and pollen provisioned to an offspring has been shows to have a linear relationship with body mass [35].

There is evidence for maternal manipulation of larval diet in facultatively eusocial bee species as well. This is one hypothesized explanation for the evolution of eusociality. Females of the halictid bee Megalopta genalis Meade-Waldo provide significantly different nutrient levels to male and female offspring, with added variation in female provisions, which results in highly varied adult female weights [36]. The small carpenter bee, Ceratina calcarata Robertson, provisions the last female offspring with significantly less pollen diversity than early (last emerging) females. The lower pollen diversity results in decreased pollen protein levels and the subsequent smaller offspring might not be reproductively viable, which coerces them to stay at the nest to raise sibling offspring [37].

\section{Nectar Chemistry and Dietary Requirements}

Nectar is mainly comprised of sugars but also contains amino acids and has trace amounts of lipids, inorganic compounds, vitamins, and plant secondary metabolites $[20,21,38]$. Nectar sugars used by bees are the hexose sugars fructose and glucose, and the disaccharide sucrose, which is comprised of glucose and fructose. Hexose sugars aren't generally found in plant phloem, suggesting a change in production of the sugars that are secreted in the nectaries [39, p. 195]. Most nectars contain all three sugars, while few contain hexose sugars 
alone [40]. The sugar composition is highly variable due to biotic and abiotic influences in the plant and environment [39, p. 198].

High sugar concentrations offer a greater energetic reward for bees, but as the concentration increases so does the viscosity of the nectar, which makes it harder for bees to imbibe nectar with their tongues (labium with maxilla and palp sheath) [41]. The optimal sugar concentration in nectar for bumble bees is between 50 and $65 \%$ for sucrose alone [42], but many factors may affect imbibition for different bee species, such as ambient pressure [43]. Solitary orchid bees [44] and male carpenter bees [45] have been documented to manipulate nectar sugar concentrations by dehydrating them with different tongue or mouth movements. There have been no studies on the optimal concentration ranges for solitary bee species. Concentration is not the only factor affecting uptake of nectar by bees. Nectary placement in a flower, tongue length, and body mass are important factors influencing bumble bee nectar uptake [42]. Information for many solitary bee species and regarding optimal conditions for nectar uptake is lacking.

There are several eco-physiological benefits to high sugar concentrations in nectar. Bee foraging distance has been found to increase logarithmically with body size as measured by the inter-tegular distance [46], with larger bees able to forage much farther than small solitary bees. Foraging distance varies greatly with different social and ecological conditions and many solitary bee species have not been evaluated for foraging distance. Sugar concentrations in nectar may increase foraging distances for bees but has been studied only in honey bees. They have been found to adjust sugar concentrations in their crop depending on foraging distance and foraging task and the energetic requirements [47]. Eusocial insects with nectar stores may be able to use those stores to increase thoracic temperatures and allow for flight in suboptimal temperatures. High sucrose concentrations have a positive effect on thoracic temperatures of bumble bees, with an observed increase of 1-2 degrees Celsius above ambient temperature [48]. Thoracic temperature response to sugar concentration has not been studied in solitary bee species. However, higher sugar levels should allow greater foraging per unit volume of nectar because sugar is used as the metabolic fuel for flight. Sugar concentration also affects growth and development of bee larvae. Larvae in the family Megachilidae have higher larval weights when fed increased sugar concentrations [49]. High sugar concentrations may result in a more energy-laden food. We found no literature to support this idea, but if this is the case, it suggests that adult foraging might be higher per unit volume of nectar imbibed and larval development might be increased per unit of provision.

Amino acids are the most abundant nutritional component of nectar after sugars but are generally thought to be less important as a nutritional source in nectar than they are in pollen [21,38]. Amino acids may affect the taste of nectar [50] or the microbial communities in nectar, which could in turn affect sugar constituents or concentration in nectar [21]. It is debated whether amino acid concentrations are selected for by bees or whether they are associated with a plant species [40]. Flowers with very high amino acid concentrations in nectar are visited more by pollinators, such as lepidopterans, that forage for nectar as their only energy and nutritional resource [38]. This compared to bees, which forage for nectar as a source of flight energy and nutrition and pollen as a source of adult and larval nutrition.

There are conflicting findings on inter- and intraspecific constancy in composition and concentrations of amino acids in nectar of flowers. Baker and Baker [40] found that intraspecific amino acid composition and concentration were highly conserved, while Gardener and Gillman [50] found intraspecific constancy in amino acid composition, but greater intraspecific variation in concentration. Many plants have high levels of the amino acid proline in their nectar, which is important for flight muscle metabolism and function [39, pg. 200] [51]. Minor nutrients that can be found in nectar are lipids, minerals, and secondary plant compounds. These are found at trace amounts, but may have a large impact, causing greater floral visitation by bees [21].

\section{Pollen Chemistry and Dietary Requirements}

Pollen is the major source of protein, free amino acids, starch, sterols, lipids, vitamins, and inorganic elements for bees $[20,21,52]$. Sugars are present in pollen but at low concentrations [53]. Fresh pollen from a flower goes through several biochemical changes from the time it is collected by bees at the flower to storage in a hive or placed as a loaf with an egg. This is due to the combination with nectar as well as any chemicals or microbes transferred from the honey stomach (proventriculus) and changes occurring once stored in the hive/nest $[21,52,54]$. Many studies on the chemistry of pollen and nectar have analyzed honey bee-collected pollen, rather than pollen collected directly from flowers [52], which is most likely due to the amount of pollen needed for accurate chemical analysis. It should be kept in mind that what is collected at the flower can be significantly different from pollen that is carried on the bee in pollen brushes or baskets (scopa or corbiculae) or pollen that is fed or given to larvae for growth and development. Transformation of pollen chemistry may also differ for different bee species, depending on chemical and microbial processes associated with each species.

Protein makes up the largest composition of pollen and has been found to make up approximately $2-60 \%$ of the dry mass in hand-collected pollens; this varies interspecifically across vascular plant taxa $[21,52]$. Proteins are broken down to their respective amino acids, which are then absorbed and used in many different essential physiological processes. Bees are efficient at nitrogen assimilation from ingested proteins; some bee species retain anywhere from 35 to $50 \%$ of dietary nitrogen and some as high as $87 \%$ [52]. Presently, information on minimum or optimum dietary protein levels is available for only for honey bees and stingless bees (Meliponinae). For optimum brood rearing a colony of honey bees requires pollen sources with approximately $20-30 \%$ protein; below these levels (5-10\%) brood production 
is not initiated even by consuming more pollen [55]. In comparison, a colony of stingless bees, which are eusocial bees that are much smaller than honey bees, have stores of pollen that contain similar levels of protein content required by honey bees [55]. Many wild bee species are not eusocial and therefore may require different minimal/optimal protein levels.

Free amino acids are also abundant in pollen and many are the limiting dietary component of pollen for bees. If there are not enough of the essential amino acids in pollen, bees will need to collect more pollen to provide adequate nutrition for their larvae [21]. Most pollens contain all essential amino acids required by bees, with contents and concentrations varying interspecifically [52]. The seminal paper for amino acid requirements in bees is by deGroot [56]. He determined that there are 10 essential amino acids for honey bees, and he estimated their minimum concentrations. These include, with minimum values expressed as percent of protein, arginine (3.0), histidine (1.5), lysine (3.0), tryptophan (1.0), phenylalanine (2.5), methionine (1.5), threonine (3.0), leucine (4.5), isoleucine (4.0), and valine (4.0). Presently, there have not been any studies to determine if required essential amino acids are ubiquitous across bee taxa, and if the minimum requirements are the same as honey bees. Several nonessential amino acids are also present at high levels in honey bee collected pollen; these include proline, glutamic acid, aspartic acid, leucine, and lysine [57] (Szczesna 2006).

Nutritional components that make up a small portion of nutrients in pollen have not been studied to as great an extent as protein and amino acid content. These include sterols, starches, lipids, vitamins, and minerals. Pollen is the only significant source of sterols for bees, and sterols are an essential nutrient. Sterols make up less than $1 \%$ dry weight in pollen for most plant species but are important for biological processes such as hormone production. The most important sterols for honey bees are cholesterols, which are usually in the form of 24-methylene cholesterol [52]. Plant species generally contain less than $1 \%$ starch in their pollen but concentrations up to $22 \%$ have been found. It's thought that bees have a harder time digesting starch. Consequently, plants that are primarily bee pollinated have lower levels of this nutrient [52]. Lipids are obtained exclusively through pollen. Lipid content of pollen is generally less than $10 \%$ of dry pollen mass. However, lipid contents greater than $10 \%$ are considered attractive to bees $[20,21,52]$. The outer sheath of pollen grains, called the "pollenkitt", contains several different lipids and it is thought that most of the lipids in pollen are contained in this layer [52]. Many different watersoluble, and few fat-soluble vitamins are found in pollen [52]. Vitamin deficiencies can lead to inhibited hypopharyngeal gland development and decreased brood rearing in honey bees. There is little known about vitamins for bee species other than honeybees, such as solitary bees [52]. Minerals are also found at low levels but may play an important role in several aspects of bee development and health. For example, zinc nutrition is important for honey bee survival and without enough in the diet there is low to no brood rearing [58].

\section{Secondary Plant Compounds in Nectar and Pollen}

There have been several reported cases of both harmful and beneficial compounds in nectar and pollen. The costs or benefits that a bee species receives from a secondary plant compound depend on several factors. For example, the nectar alkaloid, gelsamine, produced by Carolina yellow jasmine, Gelsemium sempervirens L., is known to have sublethal effects on some bees. High concentrations of gelsamine decrease oocyte development in subordinate bumble bees but have no effect on larger bumble bees. At the bumble bee colony level, the effects are more strongly seen in smaller less dominant workers [59]. Gelsamine is also a deterrent to foraging for nectar and pollen for the solitary Blue Orchard Bee adult, Osmia lignaria Say, but does not affect the development of larvae when introduced into their diet [60]. This suggests that different effects can be seen across life stages for various species. Secondary plant compounds may also have positive effects on a bee post ingestion. The nectar alkaloid anabasine was found to strongly decrease Crithidia bombi Leger parasite loads when its bumble bee host, $B$. impatiens, was fed high concentrations [61-63]. Bees may be self-medicating with secondary compounds in nectar. Richardson et al. [64] found that bumble bees infected with Crithidia bombi parasites increased foraging time on nectars high in iridoid glycoside concentrations, produced by the turtlehead plant, Chelone glabra L. Self-medicating was not seen with infection by the parasitoid fly larva Physocephala tibialis L. This medicinal effect could be beneficial for many of the bee species that can tolerate this alkaloid. There has also been evidence in honey bees of self-medication with secondary plant compounds [65].

\section{Probiotics of Pollen and Nectar}

Study of the gut microbiome of bees, and of probiotics in pollen and nectar are new areas of research for bees. Most information regarding probiotics comes from investigations on honey bees with both positive and negative effects recorded. Microbes have been identified in many different pollen and nectar sources [66-69], and provisions of bees [69]. The dominant gut flora for many native wild bees seem to come from pollen and nectar [69], but honey bees and bumble bees differ in that brood bacteria are determined by nurse flora, or social transmission [70, 71]. McFrederick and Rehan [72] determined that pollen diversity is not a strong predictor of bacterial diversity in provisions for a solitary bee, Ceratina calcarata, but a species-specific relationship was found between pollen of some plant species and bacteria. This may be significant if certain bacteria are associated with increased or decreased fitness for bees. More research is needed to determine if this is the case and if there are similarities in bee species.

A recent review of probiotics for honey bees reports several studies that show positive effects such as increased immunity to different diseases, increased egg laying, and stronger colony production, but higher mortality was also reported [73]. Schwarz et al. [74] showed that newly emerged 
worker honey bees, treated with microbial symbiont species, were negatively affected, decreasing gene expression and consequently increasing susceptibility to nutritional stress and the protozoan Lotmaria passim Schwarz. This raises concern about antibiotic treatment of honey bee hives and early alteration of gut microbiome for bees. Early treatment with antibiotics may kill beneficial symbionts and lead to poor immunity and ability to deal with subsequent stressors. Bumble bees, just like honey bees, show positive and negative effects from treatment with probiotics. Bombus terrestris colonies treated with Lactobacillus kunkeei Edwards et al. and Lactobacillus crispatusa Moore and Holdeman were less susceptible to pollen stress and exhibited increased drone production but with lower total drone weights [75]. We could find no studies of immune response in solitary bee species upon administration of a probiotic.

\section{Quality, Quantity, and Diversity}

A question that many conservation biologists are, or rather should be, asking is whether the nutritional quality of plants within the landscape matters for resident bees. Nutritional stress can lead to several problems as demonstrated with the honey bee. In honey bees, nutritional stress can lead to poor foraging ability by a colony and individuals [76, 77], and decreased longevity [78]. High quality diets in honey bees have been shown to reduce stress in bees exposed to Nosema apis Zander [79], Nosema ceranae Fries et al. [19, 79], and Varroa destructor Anderson and Trueman [79]. A similar dynamic has been shown with pesticide exposure in honey bees $[79,80]$ and exposure of bees to the Deformed Wing Virus [79]. Much of the information we have on nutritional quality comes from the honey bee with less from commercially reared bumble bee species. Little information is available on solitary bees.

Pollen quality is measured more often than nectar quality when analyzing growth and development of larvae, and protein and amino acid content have been the most common determinates of pollen quality. Higher amounts of total amino acid and polypeptide content has repeatedly been shown to be beneficial to bees. Generally, if pollen has high protein content is high in pollen the total amino acid content will also be high. Free amino acid content may be significantly different from protein and total amino acid content and therefore a better predictor of pollen quality [21, 79]. In bumble bees and solitary bees, forage plant pollen with higher protein, amino acid, and free amino acid contents has been shown to increase larval weights, egg production, pollen utilization efficacy, and syrup or nectar collection [52, 81-84]. Fewer studies have focused on sterols as a measure of pollen quality but a recent study by Moerman et al. [85] showed the importance

90.sterols play in the development of bumble bee larvae. Pollen that is higher in quality results in an increase in thoracic temperature of bumble bees [86], although in this study, pollen was tested for digestibility rather than nutritional content. Pollen influence on thoracic temperature has not been tested for solitary bees. In honey bees, a diverse diet ensures collection of essential nutrients and requires diverse plant species in a foraging area [87].

Pollen that is of high quality for one species may not be the same quality for another species. It has been demonstrated several times that different bee species are unable to develop adequately on the same diets $[88,89]$. This has been observed in both polylectic bees [89] and oligolectic bees [88]; therefore, pollen quality is defined by the bee species that associate with a given plant species. Differences in the ability to develop to adulthood may be due to toxins found in pollen that only some bee species can tolerate $[88,90]$ or differences in the ability to digest various pollens [52].

Nutritional content is not the only predictor of pollen nutritional quality. An important aspect of pollen nutrition is its digestibility by different bee species because of its hard, structural exterior (pollenkitt) and interior (intine). These are both protective barriers that prevent degradation of pollen grains and resist digestion, so organisms that consume pollen must have adaptations for adequate nutrient absorption during digestion [52]. Pollen that is stored in a hive or nest by honey bees, bumble bees, and solitary bees for provisioning their eggs is mixed with nectar and microbes throughout the collection process; this mixture provides initial breakdown of the pollen. Adults and larvae then process the pollen further during digestion, before excretion. Plant species with pollen that has a more complex pollenkitt and intine may be harder for bees to digest and alternatively pollen grains that are less complex may be a food source that is much easier to digest and assimilate nutrients. Few bees have been tested for digestive efficiency. This is important because different nutrients are digested and absorbed with different efficiencies. Honey bees, which are generalist bees, can process $50-98 \%$ of pollens ingested throughout their lifetime [52]. Bee species that are floral specialists may have more restrictive digestive abilities. In fact, digestibility and assimilation efficiency could be an explanation for, or at least a consequence of specialization.

Nectar, as a determinant of the nutritional quality of a plant species, has received less research attention, but sugars play an important role in development of bee larvae. Larval survival may be less dependent on nectar sugars. Solitary bees, in the family Megachilidae, had higher larval mass when fed a diet with higher sugar content [49], but there was no effect on larval survival with increasing or decreasing sugar content of food.

An area of nectar quality that has not been well explored is how nectar from different plant species affects the ability of a bee species to digest pollen. There are different modes of pollen digestion for different bee species, but nectar may play an important role as it is generally mixed with pollen before it is ingested. This mixing has been shown to produce chemical changes $[21,52,54]$, which may allow for more effective digestion in bees, although to date this has not been tested. For the stingless bee, Scaptotrigona postica Latreille, digestibility was not affected by storage when compared to freshly collected pollen by bees [91]. This indicates that there may be an important biochemical change due to exposure of pollen to nectar and this occurs during foraging. 


\section{Influence of Plant Growing Conditions on Pollen and Nectar Nutrition}

Nutrition of pollen and nectar may be influenced by growing conditions of the plant. Soil fertility, $\mathrm{pH}$, moisture, competition or population dynamics may be several of the conditions that could affect pollen and nectar nutrition. Most studies to date have focused on production of pollen and nectar, which has been shown to vary with drought [92], temperature [93], plant nutrients [94, 95], and levels of herbivory [96]. Nutrient availability in the soil has, so far, been the only factor tested for its effect on nutrients in pollen and nectar. Ceulemans et al. [97] found that sugars and free amino acids in pollen and nectar were affected by nutrient availability for Sucissa pratensis Moench. Overall, the total concentration of amino acids increased in the pollen and nectar of fertilized plants, but individual amino acids responded differently to fertilization. Nectar sugars were slightly different, with lower glucose concentrations in fertilized plants. Bumble bees (Bombus terrestris L.) that visited the fertilized plants in this study tended to have higher mortality rates than those visiting control plants. A similar result was also found by Hoover et al. [98] who observed bumble bees collecting artificially enhanced nectar.

\section{Nutrition and Flower Visitation}

Different bee species have been observed to visit the same plant species at different rates, which is sometimes referred to as foraging preference. Different plant characteristics may be influencing bee forage behavior and many characteristics may be working together to influence bee vitiation to different plant species [99]. These include but are not limited to floral display [100, 101], volatiles [102], color [103], and nutritional value $[17,104]$. If bees can assess nutritional resources, they may be able to select highly nutritious resources for the rearing of brood and their own energetic needs, while minimizing energy expenditures during foraging.

Pollen provides the majority of a bee's nutritional and developmental requisites, and therefore has been the focus of studies examining the influences on bee visitation. Bees are not always observed to select more nutritious pollen and nectar sources. Honey bees and bumble bees collect pollen differently. Bumble bees (Bombus terrestris and Bombus pascuorum Scopoli) have been found to collect pollen with significantly higher protein and essential amino acid levels than pollen collected by honey bees [105]. Honey bees in this same study focused on quantity rather than quality. Leonhardt and Bluthgen [105] also found some overlap in plant species visited by B. terrestris and Bombus pascuorum, but in general, these two bee species visited a different composition of plant species. Differences in nutritionally modified foraging behaviors were also observed by Somme et al. [104] in Bombus lapidaries L. and B. pascuorum, which were observed to collect pollen with high concentrations of essential amino acid and high phytosterol content, compared to B. terrestris and Bombus hypnorum L., which collected pollen with lower concentrations of essential amino acids and phytosterols, and a larger amount of pollen. Bombus impatiens has been found to prefer pollen with high protein to lipid ratios and were most attracted to ratios of 5:1 and 10:1, if concentrations were below a certain threshold, as protein and lipid concentrations increased $B$. impatiens consumption of the diet decreased [17]. Many different bee species may have highly adapted preferences for specific nutritional content. We could find no studies of solitary bee species and their assessment of the nutritional value of floral resources.

\section{Bee Forage and Climate Change}

Rapidly rising $\mathrm{CO}_{2}$ levels and other shifts in the environment due to climate change are among the many uncertainties about the future of bees and the plants they rely on for their nutritional needs. Plant species diversity, distributions, and spread of invasive plant species are all affected by climate change [106]. Ziska et al. [107] determined that protein levels in pollen stores of North American bees are already showing a decreasing concentration with increasing atmospheric $\mathrm{CO}_{2}$ levels. This is concerning because higher protein levels are associated with higher fitness [52, 81-84]. Due to potentially varying plant species response to climate change, generalist bees that forage on many different pollen and nectar sources may have an advantage over specialists in the face of climate change [108]. A comprehensive review by Goulson et al. [12] points out that climate change may work in conjunction and might even be synergistic with other stressors that bees face.

\section{Conclusions}

Regarding native wild bee nutrition, we know that bees require pollen and nectar as a source for proteins, amino acids, carbohydrates, lipids, minerals, vitamins, and many other compounds. Requirements for native wild bees are poorly known and highly variable due to their diverse characteristics and the fact that many solitary bee species are hard to rear in an environment suitable for study. Our understanding of wild bee nutrition is based upon data collected from bumble bees. Nectar nutrition and quality are associated with higher sugar concentrations for bumble bees, but these aspects are not known for solitary bees. Pollen rich in proteins, essential amino acids, and lipids, is expected to be of high quality, but there is evidence that at high concentrations some nutrients may deter foraging by bumble bees. There are also different foraging behaviors for various bumble bee species based on specific nutrients in pollen and nectar. While this pattern is likely to apply to many solitary bee species, there is currently no unified concept regarding wild bee nutrition, and the likelihood of developing such a concept appears low. The growing body of research on probiotics and the enhancement of nutrition for bees is promising, but more research is needed to determine the health effects on native wild bees.

A few common aspects of nutrition appear to be shared by most or all bees. Nutritional stress is brought on if the essential nutrients in pollen are insufficient or the ratios of these nutrients are unbalanced. This deficiency can lead to decreased fitness. Bee species vary in their requirements for different amounts of essential nutrients, but probably all 
bees require every one of them. Without adequate levels of carbohydrates in nectar, bees cannot maintain enough energy to perform daily tasks such as foraging, colony maintenance, rearing brood, or constructing and provisioning nests.

To increase our effectiveness in bee conservation and to enhance their diversity and abundances, we need to further investigate the physiological basis of limiting nutrients for both bumble bee and solitary bee species. We could find only one study that has addressed this, for amino acids, and the study focused on honey bees [56]. A comprehensive study on the nutritional requirements of bumble bee and solitary bee species has not yet been completed. There is also little known about the foraging preference or behaviors of solitary bees. This information would help conservation biologists to develop lists of forage plant species that would be best suited for reservoir plantings.

Environmental conditions and their effects on pollen and nectar nutritional content are of great importance to conservation of native wild bees. Decreased survival of bumble bees with increased soil fertility and pollen nutritional levels [98] is cause for concern, especially in landscapes continually enhanced by human activity such as agricultural landscapes and residential gardens. That phenomenon is also contradictory to the evidence that honey bee nutrition can offset the deleterious effects of exposure to pesticides, diseases, and pests. If native wild bees react differently to increased pollen and nectar nutritional levels, then comparing their nutritional needs to honey bees is misleading. Honey bee research on stress reduction with high quality nutrition is promising, but more research is needed for native wild bees. Self-medication by native wild bees suggests that this is a promising area of research. The impact of nutritional status as a cumulative process across several generations of bees is another area of conservation research that needs to be addressed. If poor nutrition is transferred from a founding reproductive female to her offspring there may be consequences for resulting populations of that species. This research question, as all the nutrition queries previously mentioned, will be much easier to investigate with bee species that can be reared in a laboratory setting or other controlled environments.

Overall, there are major gaps in knowledge of native wild bee nutrition. Bumble bee nutrition research is receiving more attention and we soon should be able to compare similarities between bumble bees and honey bees. Solitary bees will need much more attention in the future, especially because the solitary life history strategy for bees is dominant in north temperate biomes. Without comprehensive knowledge of the basic nutritional needs of native wild bees we may be at a disadvantage in developing strategies for their conservation. For example, Ceulemans et al. [97] determined that increased soil nutrients had a negative effect on pollen nutritional content and as a result $B$. terrestris colonies showed decreased fitness. If this could potentially be exhibited on a population scale across large geographic regions, then the outlook for species that respond in this manner is bleak. Honey bees are an important pollinator for our crops and can substitute for some native bee pollination, but native wild bees represent highly coevolved pollination systems with our native plant communities and native crops such as insect-pollinated lowbush blueberry $[109,110]$ and cranberry [110].

\section{Conflicts of Interest}

Megan E. Leach and Frank Drummond have no conflicts of interest with this manuscript.

\section{Acknowledgments}

The authors thank Dr. Alison Dibble, Dr. Lois Stack, and Dr. L. Brian Perkins for reviewing a previous version of this manuscript and providing invaluable feedback. This research was made possible through support from the US Department of Agriculture, National Institute for Food and Agriculture, Specialty Crop Research Initiative Grant \#2011-01389, and the University of Maine and the Maine Agricultural and Forestry Experiment Station which provided a graduate student stipend and laboratory and greenhouse facilities. The Maine Agricultural and Forestry Experiment Station Journal Number is 3630. This project was also supported by the USDA National Institute of Food and Agriculture Hatch Project Number ME0-21505, through the Maine Agricultural \& Forest Experiment Station.

\section{References}

[1] A.-M. Klein, B. E. Vaissière, J. H. Cane et al., "Importance of pollinators in changing landscapes for world crops," Proceedings of the Royal Society B Biological Science, vol. 274, no. 1608, pp. 303-313, 2007.

[2] J. Ollerton, R. Winfree, and S. Tarrant, "How many flowering plants are pollinated by animals?” Oikos, vol. 120, no. 3, pp. 321326, 2011.

[3] S. G. Potts, J. C. Biesmeijer, C. Kremen, P. Neumann, O. Schweiger, and W. E. Kunin, "Global pollinator declines: trends, impacts and drivers," Trends in Ecology \& Evolution, vol. 25, no. 6, pp. 345-353, 2010.

[4] S. A. Cameron, J. D. Lozier, J. P. Strange et al., "Patterns of widespread decline in North American bumble bees," Proceedings of the National Acadamy of Sciences of the United States of America, vol. 108, no. 2, pp. 662-667, 2011.

[5] K. M. Smith, E. H. Loh, M. K. Rostal, C. M. Zambrana-Torrelio, L. Mendiola, and P. Daszak, "Pathogens, pests, and economics: Drivers of honey bee colony declines and losses," EcoHealth, vol. 10, no. 4, pp. 434-445, 2013.

[6] I. Koh, E. V. Lonsdorf, N. M. Williams et al., "Modeling the status, trends, and impacts of wild bee abundance in the United States," Proceedings of the National Acadamy of Sciences of the United States of America, vol. 113, no. 1, pp. 140-145, 2016.

[7] UNEP, UNEP Emerging Issues: Global honey bee colony disorders and other threats to insect pollinators, UNON, Nairobi, Kenya, 2010.

[8] P. Neumann and N. L. Carreck, "Honey bee colony losses," Journal of Apicultural Research, vol. 49, no. 1, pp. 1-6, 2010.

[9] USDA-EPA, "USDA and EPA Release New Report on Honey Bee Health," Tech. Rep. 0086.13, USDA Office of Communications, 2013.

[10] S. R. Colla, J. S. Ascher, M. Arduser et al., "Documenting Persistence of Most Eastern North American Bee Species 
(Hymenoptera: Apoidea: Anthophila) to 19902009," Journal of the Kansas Entomological Society, vol. 85, no. 1, pp. 14-22, 2012.

[11] R. Winfree, "The conservation and restoration of wild bees," Annals of the New York Academy of Sciences, vol. 1195, pp. 169197, 2010.

[12] D. Goulson, E. Nicholls, C. Botías, and E. L. Rotheray, "Bee declines driven by combined Stress from parasites, pesticides, and lack of flowers," Science, vol. 347, no. 6229, Article ID 1255957, 2015.

[13] J. T. Kerr, A. Pindar, P. Galpern et al., "Climate change impacts on bumblebees converge across continents," Science, vol. 349, no. 6244, pp. 177-180, 2015.

[14] A. Nieto, S. P. M. Roberts, J. Kemp et al., European Red List of bees, Publication Office of the European Union, Luxembourg, Luxembourg, 2014.

[15] Fish and Wildlife Service, Endangered and threatened wildlife and plants; Endangered status for 49 species from the Hawaiian Islands, vol. 81, Department of the Interior Federal Register, 2016.

[16] A. S. Persson, M. Rundlöf, Y. Clough, and H. G. Smith, "Bumble bees show trait-dependent vulnerability to landscape simplification," Biodiversity and Conservation, vol. 24, no. 14, pp. 3469-3489, 2015.

[17] A. D. Vaudo, J. F. Tooker, C. M. Grozinger, and H. M. Patch, "Bee nutrition and floral resource restoration," Current Opinion in Insect Science, vol. 10, pp. 133-141, 2015.

[18] D. Naug, "Nutritional stress due to habitat loss may explain recent honeybee colony collapses," Biological Conservation, vol. 142, no. 10, pp. 2369-2372, 2009.

[19] G. Di Pasquale, M. Salignon, Y. Le Conte et al., "Influence of pollen nutrition on honey bee health: do pollen quality and diversity matter?" PLoS ONE, vol. 8, no. 8, Article ID e72016, 2013.

[20] R. Brodschneider and K. Crailsheim, "Nutrition and health in honey bees," Apidologie, vol. 41, no. 3, pp. 278-294, 2010.

[21] S. W. Nicolson, "Bee food: The chemistry and nutritional value of nectar, pollen and mixtures of the two," African Zoology, vol. 46, no. 2, pp. 197-204, 2011.

[22] C. D. Michener, The bees of the world, Johns Hopkins University Press, Baltimore, MD, USA, 2nd edition, 2007.

[23] D. Goulson, Bumblebees: Their Behavior and Ecology, Oxford University Press, Oxford, UK, 2003.

[24] D. M. Caron, L. J. Connor, R. G. Muir, A. Harman, D. Heskes, and J. Zawislak, Honey Bee Biology and Beekeeping, Wicwas Press, Kalamazoo, MI, USA, 2013.

[25] F. D. Vogt, B. Heinrich, T. O. Dabolt, and H. L. McBath, "Ovary development and colony founding in subarctic and temperature-zone bumblebee queens," Canadian Journal of Zoology, vol. 72, no. 9, pp. 1551-1556, 1994.

[26] A. L. Toth and G. E. Robinson, "Worker nutrition and division of labour in honeybees," Animal Behaviour, vol. 69, no. 2, pp. 427-435, 2005.

[27] P. P. Paoli, D. Donley, D. Stabler et al., "Nutritional balance of essential amino acids and carbohydrates of the adult worker honeybee depends on age," Amino Acids, vol. 46, no. 6, pp. 14491458, 2014.

[28] M. J. Couvillon, J. M. Jandt, J. Bonds, B. R. Helm, and A. Dornhaus, "Percent lipid is associated with body size but not task in the bumble bee Bombus impatiens," Journal of Comparative Physiology A: Neuroethology, Sensory, Neural, and Behavioral Physiology, vol. 197, no. 11, pp. 1097-1104, 2011.
[29] S. E. R. Hoover, H. A. Higo, and M. L. Winston, "Worker honey bee ovary development: Seasonal variation and the influence of larval and adult nutrition," Journal of Comparative Physiology B: Biochemical, Systemic, and Environmental Physiology, vol. 176, no. 1, pp. 55-63, 2006.

[30] T. D. Seeley, "Social foraging in honey bees: how nectar foragers assess their colony's nutritional status," Behavioral Ecology and Sociobiology, vol. 24, no. 3, pp. 181-199, 1989.

[31] A. Dornhaus and L. Chittka, "Bumble bees (Bombus terrestris) store both food and information in honeypots," Behavioral Ecology, vol. 16, no. 3, pp. 661-666, 2005.

[32] T. K. Kitaoka and J. C. Nieh, "Bumble bee pollen foraging regulation: role of pollen quality, storage levels, and odor," Behavioral Ecology and Sociobiology, vol. 63, no. 4, pp. 625-625, 2009.

[33] S. Konzmann and K. Lunau, "Divergent rules for pollen and nectar foraging bumblebees - A laboratory study with artificial flowers offering diluted nectar substitute and pollen surrogate," PLoS ONE, vol. 9, no. 3, 2014.

[34] D. Stabler, P. P. Paoli, S. W. Nicolson, and G. A. Wright, "Nutrient balancing of the adult worker bumblebee (Bombus terrestris) depends on the dietary source of essential amino acids," Journal of Experimental Biology, vol. 218, no. 5, pp. 793-802, 2015.

[35] A. Müller, S. Diener, S. Schnyder, K. Stutz, C. Sedivy, and S. Dorn, "Quantitative pollen requirements of solitary bees: Implications for bee conservation and the evolution of beeflower relationships," Biological Conservation, vol. 130, no. 4, pp. 604-615, 2006.

[36] K. M. Kapheim, S. P. Bernal, A. R. Smith, P. Nonacs, and W. T. Wcislo, "Support for maternal manipulation of developmental nutrition in a facultatively eusocial bee, Megalopta genalis (Halictidae)," Behavioral Ecology and Sociobiology, vol. 65, no. 6, pp. 1179-1190, 2011.

[37] S. P. Lawson, K. N. Ciaccio, and S. M. Rehan, "Maternal manipulation of pollen provisions affects worker production in a small carpenter bee," Behavioral Ecology and Sociobiology, vol. 70, no. 11, pp. 1891-1900, 2016.

[38] H. G. Baker, "Non-sugar chemical constituents of nectar," Apidologie, 4, no. 8, pp. 349-356, 1977.

[39] P. Willmer, Pollination and Floral Ecology, Princeton University Press, Princeton, NJ, USA, 2011.

[40] H. G. Baker and I. Baker, "Intraspecific Constancy of Floral Nectar Amino Acid Complements," Botanical Gazette, vol. 138, no. 2, pp. 183-191, 1977.

[41] W. Kim, T. Gilet, and J. W. M. Bush, "Optimal concentrations in nectar feeding," Proceedings of the National Acadamy of Sciences of the United States of America, vol. 108, no. 40, pp. 16618-16621, 2011.

[42] L. D. Harder, "Effects of nectar concentration and flower depth on flower handling efficiency of bumble bees," Oecologia, vol. 69, no. 2, pp. 309-315, 1986.

[43] B. J. Borrell, "Mechanics of nectar feeding in the orchid bee Euglossa imperialis: Pressure, viscosity and flow," Journal of Experimental Biology, vol. 209, no. 24, pp. 4901-4907, 2006.

[44] T. Pokorny, K. Lunau, T. Eltz, and J. C. Nieh, "Raising the Sugar Content - Orchid Bees Overcome the Constraints of Suction Feeding through Manipulation of Nectar and Pollen Provisions," PLoS ONE, vol. 9, no. 11, p. el13823, 2014.

[45] D. Wittmann and E. Scholz, "Nectar dehydration by male carpenter bees as preparation for mating flights," Behavioral Ecology and Sociobiology, vol. 25, no. 6, pp. 387-391, 1989. 
[46] S. S. Greenleaf, N. M. Williams, R. Winfree, and C. Kremen, "Bee foraging ranges and their relationship to body size," Oecologia, vol. 153, no. 3, pp. 589-596, 2007.

[47] K.-I. Harano and J. Nakamura, "Nectar loads as fuel for collecting nectar and pollen in honeybees: adjustment by sugar concentration," Journal of Comparative Physiology A: Neuroethology, Sensory, Neural, and Behavioral Physiology, vol. 202, no. 6, pp. 435-443, 2016.

[48] J. C. Nieh, A. León, S. Cameron, and R. Vandame, "Hot bumble bees at good food: thoracic temperature of feeding Bombus wilmattae foragers is tuned to sugar concentration," Journal of Experimental Biology, vol. 209, no. 21, pp. 4185-4192, 2006.

[49] L. Burkle and R. Irwin, "Nectar sugar limits larval growth of solitary bees (hymenoptera: Megachilidae)," Environmental Entomology, vol. 38, no. 4, pp. 1293-1300, 2009.

[50] M. C. Gardener and M. P. Gillman, "The taste of nectar - A neglected area of pollination ecology," Oikos, vol. 98, no. 3, pp. 552-557, 2002.

[51] A. M. T. Beenakkers, D. J. Van der Horst, and W. J. A. Van Marrewijk, "Insect flight muscle metabolism," Insect Biochemistry, vol. 14, no. 3, pp. 243-260, 1984.

[52] T. H. Roulston and J. H. Cane, "Pollen nutritional content and digestibility for animals," Plant Systematics and Evolution, vol. 222, no. 1-4, pp. 187-209, 2000.

[53] J. H. Cane, D. R. Gardner, and P. A. Harrison, "Nectar and pollen sugars constituting larval provisions of the alfalfa leafcutting bee (Megachile rotundata) (Hymenoptera: Apiformes: Megachilidae)," Apidologie, vol. 42, no. 3, pp. 401-408, 2011.

[54] H. Human and S. W. Nicolson, "Nutritional content of fresh, bee-collected and stored pollen of Aloe greatheadii var. davyana (Asphodelaceae)," Phytochemistry, vol. 67, no. 14, pp. 1486-1492, 2006.

[55] E. W. Herbert Jr., H. Shimaunki, and D. Caron, "Optimum protein levels required by honey bees (Hymenoptera, Apidae) to initiate and maintain brood rearing," Apidologie, vol. 8, no. 2, pp. 141-146.

[56] A. P. DeGroot, "Protein and amino acid requirements of the honeybee (Apis Mellifica L.)," Physiologia Comparata Et Oecologia, vol. 3, pp. 197-285, 1953.

[57] T. Szcezesna, "Protein content and amino acid composition of bee-collected pollen originating from Poland, South Korea, and China," Journal of Apicultural Science, vol. 50, no. 2, pp. 91-99, 2006.

[58] G. Zhang, W. Zhang, X. Cui, and B. Xu, "Zinc nutrition increases the antioxidant defenses of honey bees," Entomologia Experimentalis et Applicata, vol. 156, no. 3, pp. 201-210, 2015.

[59] J. S. Manson and J. D. Thomson, "Post-ingestive effects of nectar alkaloids depend on dominance status of bumblebees," Ecological Entomology, vol. 34, no. 4, pp. 421-426, 2009.

[60] S. E. Elliott, R. E. Irwin, L. S. Adler, and N. M. Williams, “The nectar alkaloid, gelsemine, does not affect offspring performance of a native solitary bee, Osmia lignaria (Megachilidae)," Ecological Entomology, vol. 33, no. 2, pp. 298-304, 2008.

[61] W. E. Anthony, E. C. Palmer-Young, A. S. Leonard, R. E. Irwin, and L. S. Adler, "Testing dose-dependent effects of the nectar alkaloid anabasine on trypanosome parasite loads in adult bumble bees," PLoS ONE, vol. 10, no. 11, 2015.

[62] L. L. Richardson, L. S. Adler, A. S. Leonard et al., "Secondary metabolites in floral nectar reduce parasite infections in bumblebees," Proceedings of the Royal Society B Biological Science, vol. 282, no. 1803, Article ID 20142471, 2015.
[63] E. C. Palmer-Young, B. M. Sadd, R. E. Irwin, and L. S. Adler, "Synergistic effects of floral phytochemicals against a bumble bee parasite," Ecology and Evolution, vol. 7, no. 6, pp. 1836-1849, 2017.

[64] L. L. Richardson, M. D. Bowers, and R. E. Irwin, "Nectar chemistry mediates the behavior of parasitized bees: Consequences for plant fitness," Ecology, vol. 97, no. 2, pp. 325-337, 2016.

[65] S. Erler and R. F. Moritz, "Pharmacophagy and pharmacophory: mechanisms of self-medication and disease prevention in the honeybee colony (Apis mellifera)," Apidologie, vol. 47, no. 3, pp. 389-411, 2016.

[66] Y. Jojima, Y. Mihara, S. Suzuki, K. Yokozeki, S. Yamanaka, and R. Fudou, "Saccharibacter floricola gen. nov., sp. nov., a novel osmophilic acetic acid bacterium isolated from pollen," International Journal of Systematic and Evolutionary Microbiology, vol. 54, no. 6, pp. 2263-2267, 2004.

[67] S. Fridman, I. Izhaki, Y. Gerchman, and M. Halpern, "Bacterial communities in floral nectar," Environmental Microbiology Reports, vol. 4, no. 1, pp. 97-104, 2012.

[68] S. Álvarez-Pérez, C. M. Herrera, and C. de Vega, “Zooming-in on floral nectar: A first exploration of nectar-associated bacteria in wild plant communities," FEMS Microbiology Ecology, vol. 80, no. 3, pp. 591-602, 2012.

[69] Q. S. McFrederick, J. M. Thomas, J. L. Neff et al., "Flowers and Wild Megachilid Bees Share Microbes," Microbial Ecology, vol. 73, no. 1, pp. 188-200, 2017.

[70] P. Engle and N. A. Moran, "The gut microflora of insects diversity in structure and function," FEMS Microbiology Reviews, vol. 37, no. 5, pp. 699-735, 2013.

[71] W. K. Kwong and N. A. Moran, "Gut microbial communities of social bees," Nature Reviews Microbiology, vol. 14, no. 6, pp. 374-384, 2016.

[72] Q. S. McFrederick and S. M. Rehan, "Characterization of pollen and bacterial community composition in brood provisions of a small carpenter bee," Molecular Ecology, vol. 25, no. 10, pp. 2302-2311, 2016.

[73] M. C. Audisio, "Gram-Positive Bacteria with Probiotic Potential for the Apis mellifera L. Honey Bee: The Experience in the Northwest of Argentina," Probiotics and Antimicrobial Proteins, vol. 9, no. 1, pp. 22-31, 2017.

[74] R. S. Schwarz, N. A. Moran, and J. D. Evans, "Early gut colonizers shape parasite susceptibility and microbiota composition in honey bee workers," Proceedings of the National Acadamy of Sciences of the United States of America, vol. 113, no. 33, pp. 93459350, 2016.

[75] A. Billiet, I. Meeus, M. Cnockaert et al., "Effect of oral administration of lactic acid bacteria on colony performance and gut microbiota in indoor-reared bumblebees (Bombus terrestris)," Apidologie, vol. 48, no. 1, pp. 41-50, 2017.

[76] D. J. Schulz, Z.-Y. Huang, and G. E. Robinson, "Effects of colony food shortage on behavioral development in honey bees," Behavioral Ecology and Sociobiology, vol. 42, no. 5, pp. 295-303, 1998.

[77] H. N. Scofield and H. R. Mattila, "Honey bee workers that are pollen stressed as larvae become poor foragers and waggle dancers as adults," PLoS ONE, vol. 10, no. 4, 2015.

[78] H. Wang, S.-W. Zhang, Z.-J. Zeng, and W.-Y. Yan, "Nutrition affects longevity and gene expression in honey bee (Apis mellifera) workers," Apidologie, vol. 45, no. 5, pp. 618-625, 2014.

[79] Z. Huang, "Pollen nutrition affects honey bee stress resistance," Terrestrial Arthropod Reviews, vol. 5, no. 2, pp. 175-189, 2012. 
[80] D. R. Schmehl, P. E. A. Teal, J. L. Frazier, and C. M. Grozinger, "Genomic analysis of the interaction between pesticide exposure and nutrition in honey bees (Apis mellifera)," Journal of Insect Physiology, vol. 71, pp. 177-190, 2014.

[81] A. Génissel, P. Aupinel, C. Bressac, J.-N. Tasei, and C. Chevrier, "Influence of pollen origin on performance of Bombus terrestris micro-colonies," Entomologia Experimentalis et Applicata, vol. 104, no. 2-3, pp. 329-336, 2002.

[82] J.-N. Tasei and P. Aupinel, "Nutritive value of 15 single pollens and pollen mixes tested on larvae produced by bumblebee workers (Bombus terrestris, Hymenoptera: Apidae)," Apidologie, vol. 39, no. 4, pp. 397-409, 2008.

[83] M. Vanderplanck, R. Moerman, P. Rasmont et al., "How does pollen chemistry impact development and feeding behaviour of polylectic bees?" PLoS ONE, vol. 9, no. 1, 2014.

[84] R. Moerman, N. Roger, R. De Jonghe, D. Michez, and M. Vanderplanck, "Interspecific variation in bumblebee performance on pollen diet: New insights for mitigation strategies," PLoS ONE, vol. 11, no. 12, 2016.

[85] R. Moerman, M. Vanderplanck, D. Fournier, A.-L. Jacquemart, and D. Michez, "Pollen nutrients better explain bumblebee colony development than pollen diversity," Insect Conservation and Diversity, vol. 10, no. 2, pp. 171-179, 2017.

[86] K. S. Mapalad, D. Leu, and J. C. Nieh, "Bumble bees heat up for high quality pollen," Journal of Experimental Biology, vol. 211, no. 14, pp. 2239-2242, 2008.

[87] M. Filipiak, K. Kuszewska, M. Asselman et al., "Ecological stoichiometry of the honeybee: Pollen diversity and adequate species composition are needed to mitigate limitations imposed on the growth and development of bees by pollen quality," PLoS ONE, vol. 12, no. 8, 2017.

[88] N. M. Williams, "Use of novel pollen species by specialist and generalist solitary bees (Hymenoptera: Megachilidae)," Oecologia, vol. 134, no. 2, pp. 228-237, 2003.

[89] C. Sedivy, A. Müller, and S. Dorn, "Closely related pollen generalist bees differ in their ability to develop on the same pollen diet: Evidence for physiological adaptations to digest pollen," Functional Ecology, vol. 25, no. 3, pp. 718-725, 2011.

[90] C. J. Praz, A. Müller, and S. Dorn, "Specialized bees fail to develop on non-host pollen: Do plants chemically protect their pollen?” Ecology, vol. 89, no. 3, pp. 795-804, 2008.

[91] P. G. Fernandes-Da-Silva and J. E. Serrão, "Nutritive value and apparent digestibility of bee-collected and bee- stored pollen in the stingless bee, Scaptotrigona postica Latr. (Hymenoptera, Apidae, Meliponini)," Apidologie, vol. 31, no. 1, pp. 39-45, 2000.

[92] N. M. Waser and M. V. Price, "Drought, pollen and nectar availability, and pollination success," Ecology, vol. 97, no. 6, pp. 1400-1409, 2016.

[93] H. Jakobsen, "Influence of Temperature and Floret Age on Nectar Secretion in Trifolium repens L.," Annals of Botany, vol. 74, no. 4, pp. 327-334.

[94] F. Vasek, V. Weng, R. Beaver, and C. Huszar, "Effects of Mineral Nutrition on Components of Reproduction in Clarkia ungucilata," Aliso, vol. 11, no. 4, pp. 599-618, 1987.

[95] T. Lau and A. G. Stephenson, "Effect of soil phosphorus on pollen production, pollen size, pollen phosphorous content, and the ability to sire seeds in Cucurbita pepo (Cucurbitacea)," Sexual Plant Reproduction, vol. 7, no. 4, pp. 215-220, 1994.

[96] S. Y. Strauss, J. K. Conner, and S. L. Rush, "Foliar herbivory affects floral characters and plant attractiveness to pollinators: implications for male and female plant fitness," The American Naturalist, vol. 147, no. 6, pp. 1098-1107, 1996.
[97] T. Ceulemans, E. Hulsmans, W. Vanden Ende, and O. Honnay, "Nutrient enrichment is associated with altered nectar and pollen chemical composition in Succisa pratensis Moench and increased larval mortality of its pollinator Bombus terrestris L.," PLoS ONE, vol. 12, no. 4, 2017.

[98] S. E. R. Hoover, J. J. Ladley, A. A. Shchepetkina, M. Tisch, S. P. Gieseg, and J. M. Tylianakis, "Warming, $\mathrm{CO}_{2}$, and nitrogen deposition interactively affect a plant-pollinator mutualism," Ecology Letters, vol. 15, no. 3, pp. 227-234, 2012.

[99] E. Nicholls and N. Hempel de Ibarra, "Assessment of pollen rewards by foraging bees," Functional Ecology, vol. 31, no. 1, pp. 76-87, 2017.

[100] C. J. Essenberg, "Explaining the effects of floral density on flower visitor species composition," The American Naturalist, vol. 181, no. 3, pp. 344-356, 2013.

[101] C. J. Essenberg, "Scale-dependent shifts in the species composition of flower visitors with changing floral density," Oecologia, vol. 171, no. 1, pp. 187-196, 2013.

[102] G. A. Wright and F. P. Schiestl, "The evolution of floral scent: The influence of olfactory learning by insect pollinators on the honest signalling of floral rewards," Functional Ecology, vol. 23, no. 5, pp. 841-851, 2009.

[103] Z. Bukovac, A. Dorin, V. Finke et al., "Assessing the ecological significance of bee visual detection and colour discrimination on the evolution of flower colours," Evolutionary Ecology, vol. 31, no. 2, pp. 153-172, 2017.

[104] L. Somme, M. Vanderplanck, D. Michez et al., "Pollen and nectar quality drive the major and minor floral choices of bumble bees," Apidologie, vol. 46, no. 1, pp. 92-106, 2015.

[105] S. D. Leonhardt and N. Blüthgen, "The same, but different: Pollen foraging in honeybee and bumblebee colonies," Apidologie, vol. 43, no. 4, pp. 449-464, 2012.

[106] P. Caplat, P.-O. Cheptou, J. Diez et al., "Movement, impacts and management of plant distributions in response to climate change: Insights from invasions," Oikos, vol. 122, no. 9, pp. 12651274, 2013.

[107] L. H. Ziska, J. S. Pettis, J. Edwards et al., "Rising atmospheric $\mathrm{CO} 2$ is reducing the protein concentration of a floral pollen resource essential for North American bees," Proceedings of the Royal Society, vol. 283, no. 1828, p. 20160414, 2016.

[108] N. E. Miller-Struttmann, J. C. Geib, J. D. Franklin et al., "Functional mismatch in a bumble bee pollination mutualism under climate change," Science, vol. 349, no. 6255, pp. 1541-1544, 2015.

[109] E. Asare, A. K. Hoshide, F. A. Drummond, G. K. Criner, and X. Chen, "Economic Risk of Bee Pollination in Maine Wild Blueberry, Vaccinium angustifolium," Journal of Economic Entomology, vol. 110, no. 5, pp. 1980-1992, 2017.

[110] A. Hoshide, F. Drummond, T. Stevens et al., "What Is the Value of Wild Bee Pollination for Wild Blueberries and Cranberries, and Who Values It?" Environments, vol. 5, no. 9, p. 98, 2018. 

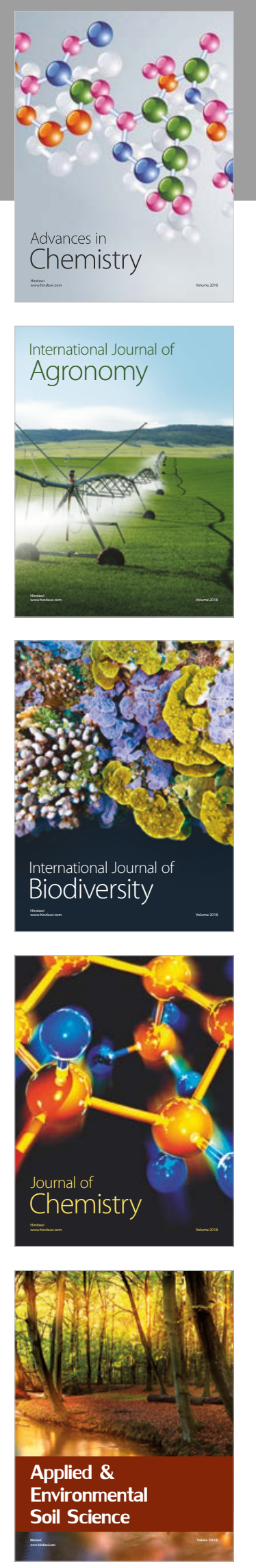

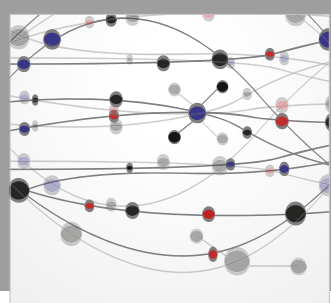

The Scientific World Journal

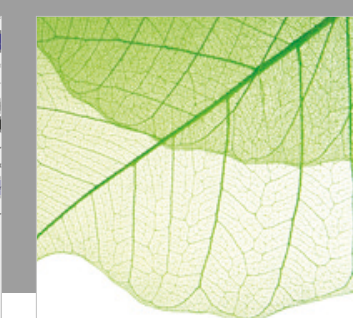

Journal of Botany

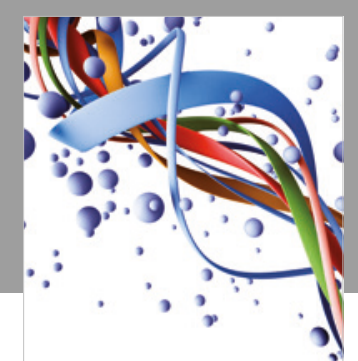

Scientifica

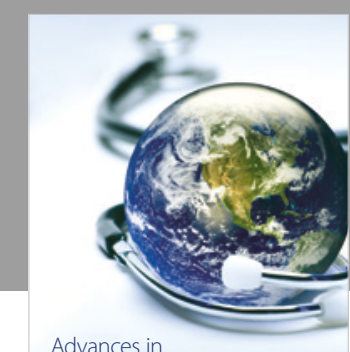

Public Health

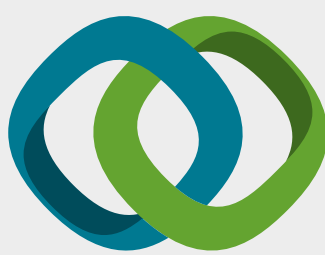

Hindawi

Submit your manuscripts at

www.hindawi.com
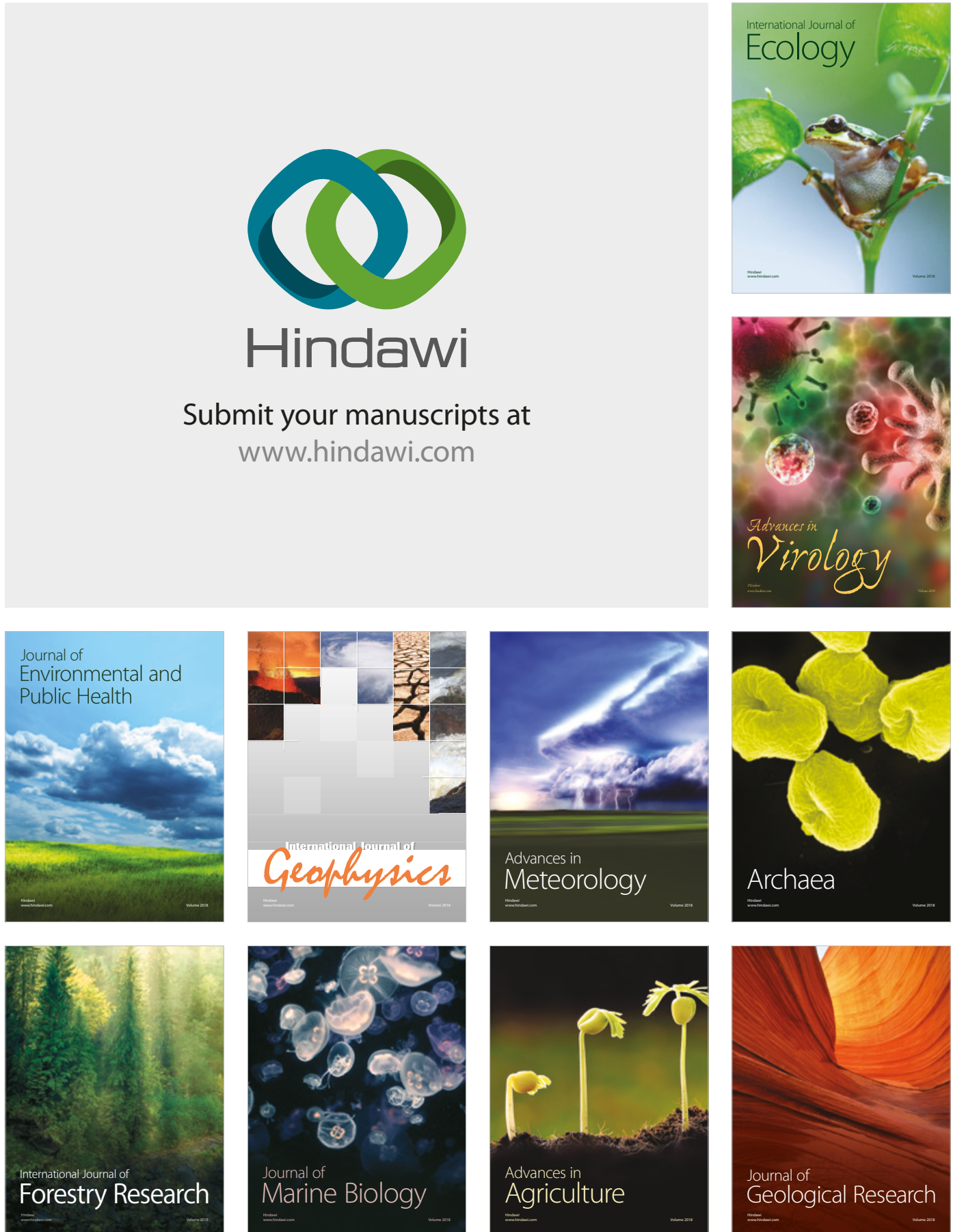

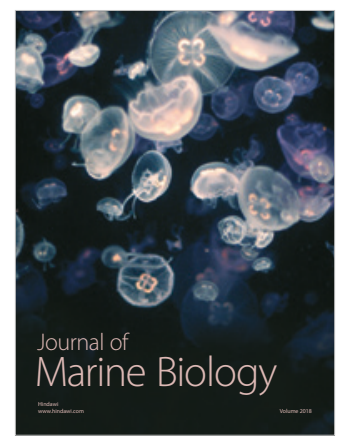

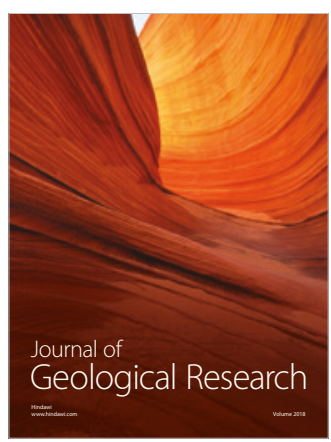

